\title{
Attention Deficits and Hyperactivity Following Inhibition of cAMP-Dependent Protein Kinase Within the Medial Prefrontal Cortex of Rats
}

\author{
Tracie A Paine', Rachael L Neve' and William A Carlezon Jr*,' \\ 'Behavioral Genetics Laboratory, Department of Psychiatry, Harvard Medical School, McLean Hospital, Belmont, MA, USA
}

\begin{abstract}
Previous work demonstrates that microinjections of dopamine DI receptor agonists and antagonists directly into the medial prefrontal cortex (mPFC) of rats can affect attention in the 5-choice serial reaction time task (5CSRTT), a rodent test analogous to the continuous performance task used to study attention in humans. These studies were designed to determine if intra-mPFC modulation of cAMPdependent protein kinase (PKA), an intracellular target of DI receptor stimulation, also affects attention. We examined the effects of localized microinfusions of the CAMP analog Sp-cAMPS (to activate PKA) or Rp-cAMPS (to inhibit PKA) in the 5CSRTT. In parallel, we examined the effects of these manipulations on activity levels in an open field, as well as on motivation and the capacity to make complex operant responses using the intracranial self-stimulation (ICSS) test. Inhibition of PKA reduced accuracy in the 5CSRTT and caused substantial increases in locomotor activity without affecting motivation or the capacity to emit operant responses at high rates. Stimulation of PKA also affected some measures of performance in the 5CSRTT, but this effect was associated with reduced capacity to respond at high rates. Viral vector-mediated disruption of cAMP response element-binding protein (CREB), a transcription factor directly activated by PKA, also reduced accuracy in the 5CSRTT, raising the possibility that acute inhibition of PKA and sustained inhibition of CREB affect attention through common mechanisms. These studies indicate that PKA inhibition within the mPFC of rats produces inattention and hyperactivity, and thus might be useful in modeling human attention disorders.

Neuropsychopharmacology (2009) 34, 2I43-2I55; doi: I0.1038/npp.2009.40; published online 22 April 2009
\end{abstract}

Keywords: attention; adenylate cyclase; CREB; prefrontal cortex; rat; reward

\section{INTRODUCTION}

The medial prefrontal cortex (mPFC) plays a key role in attention. Lesions of this region disrupt performance in a variety of attention tasks (Muir et al, 1996; Birrell and Brown, 2000; Passetti et al, 2002; Chudasama et al, 2003). There is substantial evidence that dopamine (DA) signaling within the MPFC regulates attention, consistent with the putative role of DA in cognitive functions such as working memory (Lidlow et al, 2003; Zahrt et al, 1997) and shortterm memory (Floresco and Phillips, 2001). Studies using the 5-choice serial reaction time task (5CSRTT) in rats-a rodent test analogous to the continuous performance task used to study attention in humans (Rosvold et al, 1956; Robbins, 2002) - indicate that increased activation of DA D1-like (D1) receptors within the mPFC improves attention in 'poor' performers, whereas blockade of D1 receptors

*Correspondence: Dr WA Carlezon Jr, Department of Psychiatry, Harvard Medical School, McLean Hospital, MRC 217, I I 5 Mill Street, Belmont, MA 02478, USA, Tel: + 617855 2021, Fax: + 6178552023 , E-mail: bcarlezon@mclean.harvard.edu

Received 17 February 2009; revised 17 March 2009; accepted 17 March 2009 impairs attention in 'good' performers (Granon et al, 2000). Moreover, D1 receptor stimulation improves both the attentional and working memory components in a combined working memory/attention task (Chudasama and Robbins, 2004). Thus there appears to be a narrow range of D1 receptor activity that produces optimal cognitive performance, deviations from which can be disruptive (Goldman-Rakic et al, 2000).

D1 receptor stimulation has many intracellular effects. One prominent and well-characterized effect is activation of adenylate cyclase, which increases production of cyclic Adenosine $3^{\prime}, 5^{\prime}$-monophosphate (cAMP) and activates cAMP-dependent protein kinase (PKA; Greengard et al, 1999). Downstream consequences of PKA activation include phosphorylation of the transcription factor cAMP response element-binding protein (CREB) and induction of CREBregulated genes (Carlezon et al, 2005). Alterations in PKA activity can affect some types of cognitive performance: increased PKA activity within the MPFC impairs working memory (ie, delays < $1.0 \mathrm{~min}$; Taylor et al, 1999; Runyan and Dash, 2005) and decreased PKA activity impairs shortterm memory (ie, delays $>1.5 \mathrm{~min}$; Aujla and Beninger, 2001; Runyan and Dash, 2005). However, the role of D1 
receptor-associated intracellular signaling pathways in attention has not been thoroughly characterized.

These studies were designed to extend previous findings with D1 receptor agonists and antagonists (Granon et al, 2000) by examining how alterations in PKA activity within the $\mathrm{mPFC}$ affect attention in rats. We used intra-mPFC microinfusions of the cAMP analog Sp-cAMPS to activate PKA or Rp-cAMPS to inhibit PKA; these substances directly influence CREB phosphorylation (Self et al, 1998). We measured the effects of these manipulations on attention in the 5CSRTT and on activity levels in an open field. To address the possibility that altered PKA activity within the mPFC affects performance in the 5CSRTT by altering motivation, we also examined the effects of Sp-cAMPS and $\mathrm{Rp}$-cAMPS on responding for rewarding brain stimulation using the intracranial self-stimulation (ICSS) test (Carlezon and Chartoff, 2007). Finally, to explore the possibility that acute alterations in PKA and sustained alterations in CREB within the MPFC would have similar effects on behavior, we used viral vectors to increase (by elevating expression of wild-type CREB) or decrease (by expressing a dominantnegative CREB) activity of this transcription factor (Carlezon et al, 1998).

\section{METHODS}

\section{Rats}

Male Sprague-Dawley rats (Charles River; 250-300 g at the start of the experiments) were housed in clear Plexiglas cages on a $12 \mathrm{~h} / 12 \mathrm{~h}$ light-dark cycle (lights on at 0700 hours). Before the surgery rats were housed in pairs, and after the surgery they were housed singly. Before training, rats were given 1 week to acclimate to the housing conditions with free access to food (Purina Rat Chow) and water. Rats tested in the 5CSRTT and locomotor activity studies were food restricted to $\sim 85 \%$ of their freefeeding weights beginning $24 \mathrm{~h}$ before the onset of training. In the home cage, all rats had free access to water. Experiments were conducted in accordance with the National Institutes of Health (NIH) Guide for the Care and Use of Laboratory Animals (National Academy Press, 1996) and McLean Hospital policies.

\section{Drugs}

Sp-Adenosine $3^{\prime}, 5^{\prime}$-cyclic monophosphorothioate triethylammonium salt hydrate (Sp-cAMPS) and Rp-Adenosine $3^{\prime}$, $5^{\prime}$-cyclic monophosphorothioate triethylammonium salt hydrate (Rp-cAMPS) were purchased from Sigma (St Louis, $\mathrm{MO}$ ) and dissolved in 0.1 M PBS ( $\mathrm{pH} 6.9$ ).

\section{Viral Vectors}

cDNAs for CREB, dominant-negative CREB (mCREB, which contains a point mutation at ser133 that prevents phosphorylation), and LacZ were inserted into the herpes simplex virus (HSV) amplicon HSV-PrpUC and packaged into virus using the helper $5 d l 1.2$, as described previously (Neve et al, 1997; Carlezon et al, 1998; Pliakas et al, 2001). Virus was purified on a sucrose gradient, pelleted, and resuspended in $10 \%$ sucrose. The titer of the vector stocks was $\sim 4.0 \times 10^{7}$ infectious units $/ \mathrm{ml}$.

\section{Surgery}

Rats were anesthetized with sodium pentobarbital $(65 \mathrm{mg} /$ $\mathrm{kg}$, IP) and treated with atropine sulfate $(0.25 \mathrm{mg} / \mathrm{kg}, \mathrm{SC})$ $30 \mathrm{~min}$ before the surgery. For rats in the Sp-cAMPS and Rp-cAMPS studies, surgery involved implantation of guide cannulae (26-gauge; Plastics One, Roanoke, VA) that were situated above the mPFC (relative to bregma: $\mathrm{AP}=+3.2$, $\mathrm{ML}= \pm 0.75, \quad \mathrm{DV}=-2.0 \mathrm{~mm}$ from dura (Paxinos and Watson, 1997)). Obturators and injector needles (33-gauge) extended $1.5 \mathrm{~mm}$ below the guide cannulae, into the prelimbic cortex (PrL). A subset of rats implanted with guide cannulae situated more dorsally $(\mathrm{AP}=+3.2$, $\mathrm{ML}= \pm 0.75, \quad \mathrm{DV}=-0.5 \mathrm{~mm}$ from dura) served as a comparison condition in the 5CSRTT studies. Rats in the ICSS experiment were simultaneously implanted with a monopolar, stainless-steel electrode $(0.25-\mathrm{mm}$ diameter; Plastics One) aimed at the left medial forebrain bundle at the level of the lateral hypothalamus (relative to bregma: $\mathrm{AP}=-2.8, \mathrm{ML}=1.6, \mathrm{DV}=-7.8$ from dura). The electrodes were coated with polyamide insulation except at the flattened tip. Skull screws (one of which served as the ground) and the electrode were secured to the skull with dental acrylic.

For the studies involving viral vectors, surgery involved bilateral microinjections $(1.0 \mu \mathrm{l})$ of HSV-CREB (encoding wild-type CREB), HSV-mCREB (encoding a dominantnegative form of CREB (mCREB)), or LacZ (encoding $E$. coli $\beta$-galactosidase) into the $\operatorname{PrL}$ (relative to bregma: $\mathrm{AP}=$ $+3.2, \mathrm{ML}= \pm 0.7, \mathrm{DV}=-3.5$ from dura) over $10 \mathrm{~min}$ $(0.1 \mu \mathrm{l} / \mathrm{min})$. Injectors (27-gauge) were left in place for $5 \mathrm{~min}$ to allow for diffusion following infusions and then removed, the hole was covered with bone wax and the incision closed with wound clips.

\section{5-Choice Serial Reaction Time Task}

Rats were trained as described previously (Paine et al, 2007). Sessions started with the delivery of one food pellet (45-mg, Bio-Serv, Frenchtown, NJ) and the first trial commenced on pellet retrieval. A nose poke into the magazine initiated a 5-s intertrial interval (ITI) and illuminated the 2-W house light. At the end of the ITI, a 1.0-s LED light stimulus was presented at the rear of one of the five stimulus locations (apertures). Rats had up to $5 \mathrm{~s}$ (limited hold) to make a response. A response in the illuminated aperture (correct response) triggered delivery of 1 food pellet and illuminated the $2-\mathrm{W}$ magazine light, which remained illuminated for $5 \mathrm{~s}$ following food delivery. Nose pokes in the remaining apertures during the limited hold were considered incorrect responses and triggered a 5-s time out during which the house light was extinguished. Similarly, failing to respond during the limited hold (ie, an omission) triggered a 5-s time out. Responses occurring before stimulus presentation (ie, during the ITI) were considered premature responses and also triggered a 5-s time out. Responses occurring during the time-out period had no programmed consequences. Each session ended after 90 trials or $30 \mathrm{~min}$. Performance measures of interest 
were \% accuracy ((correct responses/(correct + incorrect responses $\left.))^{\star} 100\right)$, \% omissions ((omissions/trials completed $\left.)^{\star} 100\right)$, premature responses, magazine entries, and correct response latency (the time from the stimulus onset to a correct response). Subjects were considered to have acquired the task when their accuracy was greater than $60 \%$ (chance performance in this test is 20\%) and omissions were fewer than $20 \%$ for 5 consecutive days. On reaching criterion performance (typically requiring 6-8 weeks of training), the rats underwent surgery to implant guide cannula or microinject the viral vectors.

For the studies involving the CAMP analogs, the rats were allowed to recover for 7 days and then were restabilized for 5 days before drug testing. Rats were habituated to the drug infusion procedure before the two sessions preceding testing. On test days, rats were infused with either SpcAMPS $(0.0,0.021,0.21$, or $2.1 \mathrm{nmol} / 0.5 \mu \mathrm{l}$ per side) or Rp-cAMPS $(0.0,0.21,2.1$, or $21.0 \mathrm{nmol} / 0.5 \mu \mathrm{l}$ per side) immediately before testing. The analogs were infused at a rate of $0.25 \mu \mathrm{l} / \mathrm{min}$ and allowed to diffuse for $2 \mathrm{~min}$ before removal of the injector. Dosages are within the same range as used for other studies (eg, Self et al, 1998; Taylor et al, 1999; Runyan et al, 2005), which include demonstrations that these analogs have their intended effects on CREB function. Sp-cAMPS $(21.0 \mathrm{nmol} / 0.5 \mu \mathrm{l}$ per side) caused seizures in preliminary experiments and was not tested. Doses of Sp-cAMPS and Rp-cAMPS were administered using a counterbalanced design with a minimum of 2 drug-free days between infusions.

After the dose-response relationships had been established for Sp-cAMPS and Rp-cAMPS using standard testing conditions, rats were tested under more attentionally demanding conditions whereby the duration of the ITI was shortened and made temporally unpredictable (0.5$4.5 \mathrm{~s}$ ). In this version of the task, the number of trials per session was increased to 120 . Rats were tested twice under these conditions, once following infusions of vehicle and once following infusions of either Sp-cAMPS $(2.1 \mathrm{nmol} /$ $0.5 \mu \mathrm{l}$ per side) or $\mathrm{Rp}$-cAMPS $(2.1 \mathrm{nmol} / 0.5 \mu \mathrm{l}$ per side). The order of the infusions was counterbalanced across rats. Including both the dose-response and short ITI experiments, each rat received a total of six microinfusions.

Separate rats were used for the viral vector studies. In these rats, testing was conducted in a single session 2 days after viral-mediated gene transfer, a time point at which HSV vector-induced transgene expression is maximal (Carlezon et al, 1997, 1998; Pliakas et al, 2001; Neumaier et al, 2002; Todtenkopf et al, 2006).

\section{Locomotor Activity}

Rats used in the locomotor activity studies had not been tested previously. To mimic the testing conditions used in the 5CSRTT, these rats were food restricted to $\sim 85 \%$ of their free-feeding body weights for 3 weeks before the surgery and allowed to recover for 7 days after the surgery. Locomotor activity was quantified (distance traveled, in $\mathrm{cm}$ ) in automated $(43.2 \times 43.2 \mathrm{~cm})$ activity chambers (MED Associates, St Albans, VT) over two sessions, separated by 3-4 days. In each session, rats were habituated to the activity chambers for $30 \mathrm{~min}$, infused with $\mathrm{Sp}$-cAMPS ( $2.1 \mathrm{nmol} / 0.5 \mu \mathrm{l} /$ side), Rp-cAMPS ( $21.0 \mathrm{nmol} / 0.5 \mu \mathrm{l} / \mathrm{side})$ or vehicle and immediately returned to the activity chamber for a 30-min test. Each rat was tested twice, once with SpcAMPS or Rp-cAMPS and once with vehicle. The order of drug infusions was counterbalanced across rats.

Separate rats were used for the viral vector studies. Locomotor activity was quantified for $60 \mathrm{~min}$ on the day of surgery so that subjects could be assigned to groups with similar baseline activity. Testing $(60 \mathrm{~min})$ was conducted 2 days after viral-mediated gene transfer.

\section{Intracranial Self-Stimulation}

Rats used in the ICSS tests had not been tested previously. The rats were trained on a continuous reinforcement schedule (FR1) to respond for brain stimulation (Todtenkopf et al, 2006; Carlezon and Chartoff, 2007). Lever pressing resulted in the illumination of a $2-\mathrm{W}$ house light and immediate delivery of a 0.5 -s train of square-wave cathodal pulses (0.1-ms pulse duration) at a set frequency of $141 \mathrm{~Hz}$. Responses during the 0.5 -s stimulation period did not earn additional stimulation. The stimulation current $(200-350 \mu \mathrm{A})$ was adjusted gradually to the lowest value that would sustain a reliable rate of responding (at least 40 rewards per minute).

Once rats reliably lever pressed for stimulation, they were adapted to lever press for a descending series of stimulation frequencies. Each series consisted of 15 1-min trials at each frequency. Each trial consisted of a 5-s 'priming' phase during which noncontingent stimulation was given, followed by a 50-s test phase during which the number of responses was counted and ended with a 5-s time-out period during which no stimulation was available. The stimulation frequency was then lowered by $\sim 10 \%(0.05$ $\log _{10}$ units) and another trial was started. After responding had been evaluated at each of the 15 frequencies, the procedure was repeated such that each rat was given 4 series per day (60 min of training). During training, the range of frequencies was adjusted for each rat so that only the highest 6-8 frequencies would sustain lever pressing. To characterize the functions relating response strength to reward magnitude, a least-squares line of best fit was plotted across the frequencies that sustained responding at $20,30,40,50$, and $60 \%$ of the maximum rate using customized analysis software. The threshold for responding was defined as the frequency at which the line intersected the $x$ axis (theta-0). Drug testing started when mean thresholds varied by less than $\pm 15 \%$ over three consecutive training sessions.

Drug effects were quantified using the 'curve-shift' method of analysis (Todtenkopf et al, 2006; Carlezon and Chartoff, 2007). For each rat, three rate-frequency functions ('curves') were determined immediately before drug infusions. The second and third curves were averaged to obtain the baseline (threshold and maximal response rate) parameters. Each rat was then infused with either Sp-cAMPS $(0.0,2.1 \mathrm{nmol} / 0.5 \mu \mathrm{l}$ per side) or Rp-cAMPS $(0.0,21.0 \mathrm{nmol} /$ $0.5 \mu \mathrm{l}$ per side) and tested for an additional $15-\mathrm{min}$ ratefrequency curve. Rats were tested with Sp-cAMPS and RpcAMPS; doses were administered in a counterbalanced fashion. Vehicle and drug tests were separated by 2 days, and tests of the analogs were separated by 7-10 days. 


\section{Histology}

Following the last test session, rats were anesthetized with sodium pentobarbital $(130 \mathrm{mg} / \mathrm{kg}$, IP) and transcardially perfused with $0.9 \% \mathrm{NaCl}$ followed by $4 \%$ paraformaldehyde. Brains were removed, postfixed for $24 \mathrm{~h}$ and then cryoprotected in $30 \%$ sucrose before slicing on a microtome. Sections $(40 \mu \mathrm{m})$ were mounted on slides, stained with cresyl violet and placements assessed. As described previously (Pliakas et al, 2001), we used a $0.2 \mathrm{mg} / \mathrm{ml}$ 5-bromo-4-chloro-3-indolyl $\beta$-D-galactopyranoside (X-gal; Fisher Scientific, Houston, TX) solution to detect $\beta$ galactosidase and a CREB antibody (1:1000; Upstate biotechnology, Lake Placid, NY) solution to detect CREB and MCREB.

\section{Statistical Analyses}

Performance in the 5CSRTT after intra-PFC microinfusions of Sp-cAMPS and Rp-cAMPS were analyzed using separate one-way (treatment) analyses of variance (ANOVA) with repeated measures. Baseline-dependent performance and performance on the short variable ITI version of the 5CSRTT were analyzed using two-way (performance (good $v s$ poor $) \times$ treatment, or treatment $\times$ ITI) ANOVA with repeated measures. Data from the dorsal control experiments were analyzed using paired-samples Student's $t$-tests. The effects of manipulating $\mathrm{mPFC}$ CREB function on performance in the 5CSRTT were analyzed using a twoway (treatment $\times$ session (baseline $v s$ test)) ANOVA with repeated measures. Baseline values were calculated by averaging performance during the three sessions before vector infusions. The effects of manipulating PKA or CREB function on total locomotor activity were analyzed using two-way (treatment $\times$ session (baseline $v s$ test)) ANOVAs with repeated measures. Effects on locomotor activity during the sessions were analyzed using a two-way ANOVA (treatment $\times$ time) with repeated measures. The effects of manipulating PKA on ICSS thresholds and maximal rates of responding were analyzed using separate paired-samples Student's $t$-tests. Significant main effects observed following a one-way ANOVA and all interactions were further analyzed using Fisher's protected $t$-tests. Significant main effects observed following a two-way ANOVA were further analyzed using simple main effects tests and, when appropriate, Fisher's protected $t$-tests.

\section{RESULTS}

\section{Localization of Microinfusions}

Bilateral microinfusions targeted the mPFC (Figure 1a). Microinfusions of the cAMP analogs (Figure 1b) or the viral vectors (Figure 1c) were made into the PrL subregion of the mPFC; previous work has established a critical role for this subregion in the regulation of attention in rats (Chudasama et al, 2003; Passetti et al, 2002), and it is the predominant aspect of the mPFC at this anterior-posterior level. Expression of $\beta$-galactosidase (encoded by HSV-LacZ; Figure 1c) and the other transgenes (CREB and mCREB) was strong at the time of testing (2 days after gene transfer), as demonstrated previously (Carlezon et al, 1997, 1998;
Pliakas et al, 2001; Neumaier et al, 2002; Todtenkopf et al, 2006). As would be expected, implantation of the guide cannulae and obturator assembly caused some mechanical damage to brain tissue (Figure 1b). The amount of damage was indistinguishable among groups and thus unlikely to contribute to group differences in behavior. Microscopic analysis of Nissl-stained sections indicate minimal tissue damage (gliosis, necrosis) surrounding the guide cannulae and obturators after repeated microinfusions of the cAMP analogs (Figure 1b) or surrounding the infusion site of the viral vectors (Figure 1d). Expression of CREB (not shown) was similar to that depicted previously (Carlezon et al, 1998; Pliakas et al, 2001): each microinfusion resulted in $\sim 1000$ heavily stained CREB-immunoreactive cells within a $\sim 1.0 \mathrm{~mm}$ sphere. This number likely represents an underestimation because we adjusted our immunohistochemical conditions to minimize detection of endogenous CREB. Expression of mCREB was immunohistochemically indistinguishable from the expression of CREB because the antibody cannot distinguish these two proteins (Carlezon et al, 1998). We eliminated a total of six rats from the 5CSRTT studies involving the CAMP analogs, three rats from the 5CSRTT studies involving the CREB vectors, and four rats from the ICSS studies because the microinfusion sites were located outside the PrL. These rats were distributed across the treatment conditions and it was not possible to incorporate them into homogeneous control groups because there was no systematic pattern of missed placements. In addition, we eliminated one rat from the locomotor activity studies because of guide cannula failure.

\section{PKA and Performance in the 5CSRTT}

To determine if stimulation of PKA activity in the PrL would affect performance in the 5CSRTT, rats $(n=11)$ were tested following microinfusions of the cAMP analog $\mathrm{Sp}$ cAMPS (Figure 2; Table 1). Sp-cAMPS did not affect accuracy (Figure 2a), but it did affect omissions ( $\mathrm{F}[3$, $30]=5.95, P<0.01$; Figure $2 \mathrm{~b}$ ). Post hoc analyses (Fisher's protected $t$-tests) indicated that Sp-cAMPS $(2.1 \mathrm{nmol})$ increased omissions $(P<0.01)$. None of the other measures were affected by Sp-cAMPS infusions (Table 1).

To determine if inhibition of PKA activity in the PrL would affect performance in the 5CSRTT, rats $(n=14)$ were tested following microinfusions of Rp-cAMPS (Figure 2; Table 2). Rp-cAMPS affected accuracy $(\mathrm{F}[3,39]=5.43$, $P<0.01$; Figure 2c) and omissions $(\mathrm{F}[3,39]=24.55$, $P<0.01$; Figure 2d). Post hoc analyses indicated that $\mathrm{Rp}$ cAMPS (21.0 nmol) decreased accuracy and increased omissions relative to vehicle infusions $(P$ values $<0.01)$. None of the other measures were affected by Rp-cAMPS infusions (Table 2).

We performed additional analyses to examine if modulating PKA activity within the PrL affects attention in a baseline-dependent manner. We used a median split to divide rats into groups of 'good' and 'poor' performers based on their accuracy scores following vehicle infusions. In this dataset, rats performing at $\geqslant 70 \%$ accuracy were defined as 'good' performers whereas those performing at $<70 \%$ accuracy were defined as 'poor' performers $(n=5-7$ per group). Sp-cAMPS did not differentially affect accuracy (Figure 3a) or omissions (Figure 3b) in 'good' and 'poor' 

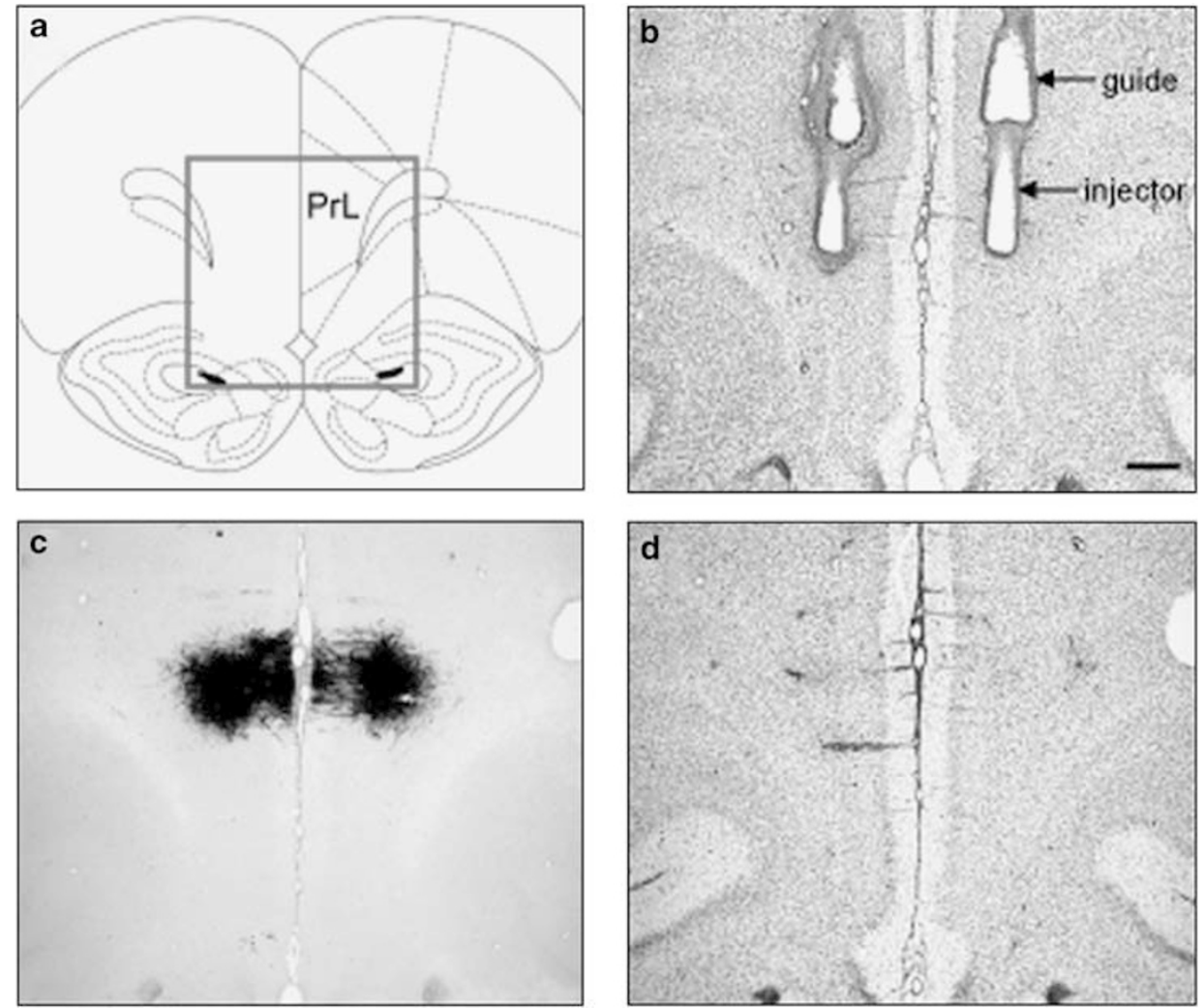

Figure I Histological examination of the medial prefrontal cortex (mPFC) after various treatments. (a) Schematic of the mPFC approximating location of cannulae placements and viral vector infusions (Paxinos and Watson, 1997). Box indicates field of view in subsequent micrographs. (b) Representative prelimbic cortex (PrL) cannula placements; scale bar $=500 \mu \mathrm{m}$. (c) Expression of $\beta$-galactosidase (darkly stained cells) within the mPFC 2 days after bilateral microinjections of HSV-LacZ into the PrL in a representative rat, demonstrating spatial selectivity. (d) An adjacent Nissl-stained section from the same brain, demonstrating lack of toxicity.

a

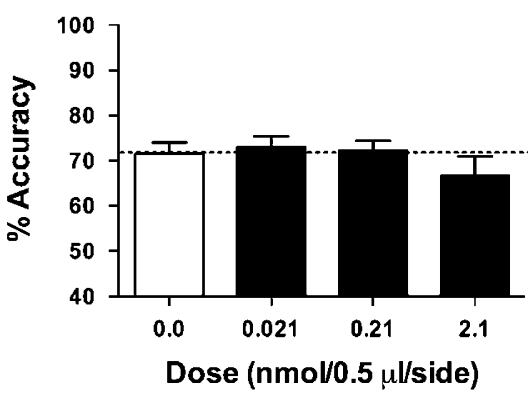

C

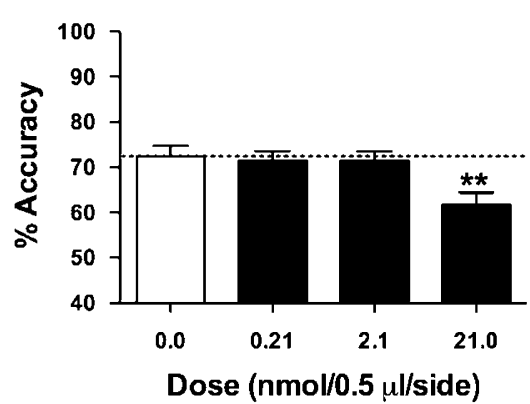

b

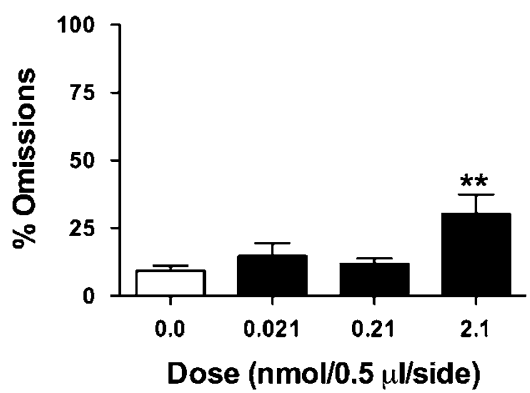

d

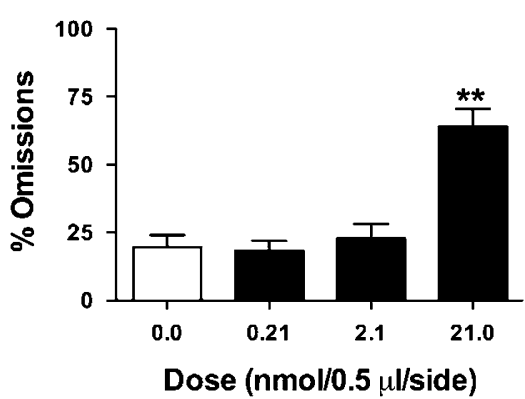

Figure 2 Effects of modulating PKA activity on 5CSRTT performance. (a) Sp-cAMPS (2.I nmol) did not affect accuracy (mean \pm SEM) but (b) increased omissions. (c) Rp-cAMPS (21.0 nmol) impaired accuracy and (d) increased omissions. Dotted line (a, c) represents performance following vehicle (0.0 nmol) infusions. $* * P<0.01$ compared to vehicle, Fisher's protected $t$-tests. 
performers; a Student's $t$-test confirmed that 'good' performers had higher accuracy than 'poor' performers following vehicle infusions $(t[9]=4.73, P<0.01)$. As reported above, Sp-cAMPS increased omissions ( $\mathrm{F}[1$, $9]=7.12, P<0.05)$; however, the increase did not reach

Table I Effects of Intra-PrL Microinfusions of Sp-cAMPS on 5CSRTT Performance

\begin{tabular}{lcccc}
\hline & $\mathbf{0 . 0}$ & $\mathbf{0 . 0 2} \mathbf{1}$ & $\mathbf{0 . 2 1}$ & $\mathbf{2 . 1}$ \\
\hline Premature responses & $21.8 \pm 3.2$ & $18.6 \pm 4.4$ & $19.3 \pm 4.4$ & $30.4 \pm 1.5$ \\
Magazine entries & $151.5 \pm 18.8$ & $148.4 \pm 18.3$ & $159.2 \pm 17.4$ & $126.8 \pm 13.7$ \\
Correct latency (s) & $0.72 \pm 0.24$ & $0.80 \pm 0.04$ & $0.77 \pm 0.36$ & $0.87 \pm 0.70$ \\
\hline
\end{tabular}

Sp-cAMPS did not significantly affect premature responses, magazine entries, or the latency to respond correctly.

Table 2 Effects of Intra-PrL Microinfusions of Rp-cAMPS on 5CSRTT Performance

\begin{tabular}{lcccr}
\hline & $\mathbf{0 . 0}$ & $\mathbf{0 . 2 1}$ & $\mathbf{2 . 1}$ & $\mathbf{2 1 . 0}$ \\
\hline Premature responses & $24.2 \pm 3.5$ & $22.6 \pm 5.3$ & $18.6 \pm 3.8$ & $27.6 \pm 6.0$ \\
Magazine entries & $139.6 \pm 8.5$ & $144.1 \pm 15.2$ & $140.9 \pm 9.8$ & $153.8 \pm 16.7$ \\
Correct latency (s) & $0.80 \pm 0.05$ & $0.84 \pm 0.04$ & $0.78 \pm 0.04$ & $0.97 \pm 0.09$
\end{tabular}

Rp-cAMPS did not significantly affect premature responses, magazine entries, or the latency to respond correctly.

a

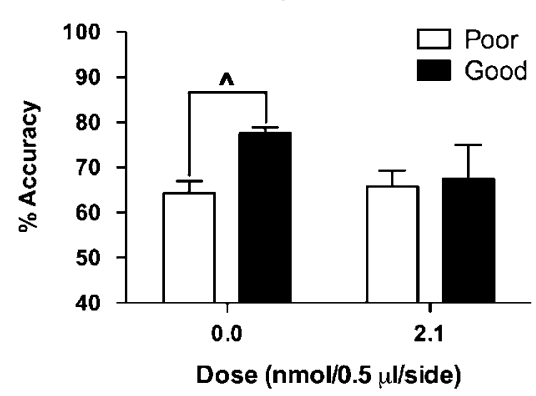

C

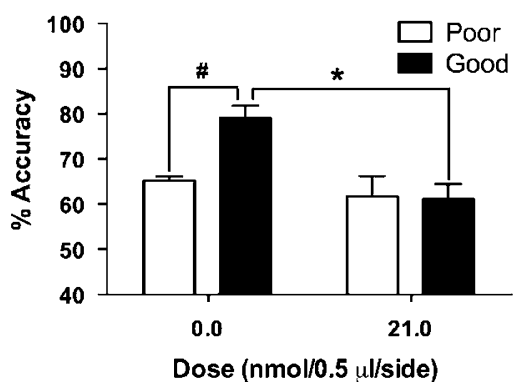

significance in either 'poor' or 'good' performers (Figure $3 \mathrm{~b}$ ). In contrast, there was a significant interaction between Rp-cAMPS and performance $(\mathrm{F}[1,12]=5.20$, $P<0.05$; Figure $3 \mathrm{c})$ such that Rp-cAMPS $(21.0 \mathrm{nmol})$ impaired accuracy in 'good', but not 'poor', performers $(P<0.05)$. As reported above, Rp-cAMPS increased omissions $(F[1,9]=43.96, P<0.01$, Figure $3 \mathrm{~d})$; simple main effects tests revealed that this was true for both 'poor' ( $\mathrm{F}[1$, $6]=31.02, P<0.01)$ and 'good' $(F[1,5]=16.97, P<0.01)$ performers.

We also investigated whether modulating PKA activity would differentially affect performance under more attentionally demanding conditions in which the ITI was shortened and made temporally unpredictable $(0.5-4.5 \mathrm{~s})$. Under challenge conditions (Table 3 ), there were main effects of ITI (delay) on accuracy $(\mathrm{F}[3,60]=11.07, P<0.01)$ and omissions $(\mathrm{F}[3,60]=73.91, P<0.01)$. Simple main effects tests revealed that accuracy improved as the duration of the ITI increased following either vehicle $(\mathrm{F}[3,30]=4.99$, $P<0.01)$ or Sp-cAMPS $(\mathrm{F}[3,30]=6.67, P<0.01)$ infusions; regardless of treatment, accuracy at the 0.5-s ITI was lower than at the 1.5-, 3.0-, and 4.5-s ITIs $(P$ values $<0.05)$. Conversely, simple main effects tests revealed that omissions decreased as the duration of the ITI increased following either vehicle $(\mathrm{F}[3,30]=17.48, P<0.01)$ or SpcAMPS $(\mathrm{F}[3,30]=7.67, P<0.01)$ infusions; regardless of treatment, omissions at the 0.5 -s ITI were greater than at the $1.5-, 3.0-$, and 4.5 -s ITIs $(P$ values $<0.05)$. However, there was no main effect of Sp-cAMPS on any performance measure, nor was there a significant interaction between $\mathrm{Sp}$ cAMPS and ITI duration. b

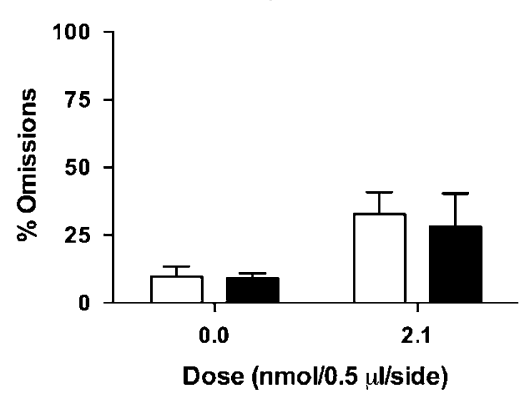

d

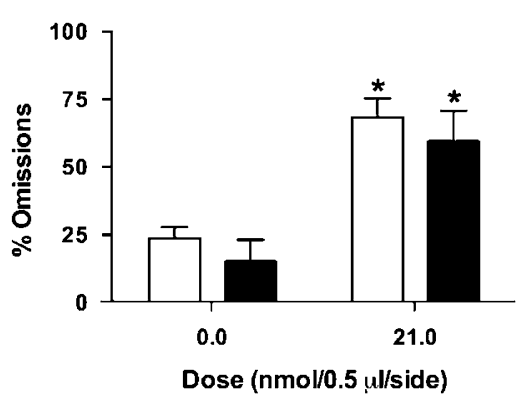

Figure 3 Baseline-dependent effects of modulating PKA activity on 5CSRTT performance. Rats were divided into 'good' and 'poor' performers based on their accuracy (mean \pm SEM) following vehicle infusions. (a, c) 'Good' performers had higher accuracy than 'poor' performers. (a, b) Sp-cAMPS (2.I nmol/ $0.5 \mu \mathrm{l} / \mathrm{side}$ ) did not differentially affect accuracy or omissions in 'good' and 'poor' performers. (c, d) Rp-cAMPS impaired accuracy in 'good' but not 'poor' performers and increased omissions in both 'good' and 'poor' performers. ${ }^{\wedge} P<0.05$, Student's $t$-test; * $P<0.05$, within-subjects comparison, ${ }^{\#} P<0.05$, between-subjects comparisons, Fisher's protected t-tests. 
Table 3 Effects of Sp-cAMPS on Performance on the Variable-Short Intertrial Interval Version of the 5CSRTT

\begin{tabular}{|c|c|c|c|c|c|c|c|c|}
\hline & \multicolumn{4}{|c|}{ Vehicle } & \multicolumn{4}{|c|}{ Sp-cAMPS ( $2.1 \mathrm{nmol} / 0.5 \mu \mathrm{l}$ per side) } \\
\hline & $0.5-\mathrm{s}$ & $1.5-\mathrm{s}$ & $3.0-\mathrm{s}$ & $4.5-\mathrm{s}$ & $0.5-\mathrm{s}$ & I.5-s & $3.0-\mathrm{s}$ & 4.5-s \\
\hline \% Omissions & $60.0 \pm 6.2$ & $39.1 \pm 6.5 *$ & $20.3 \pm 5.3 *$ & $13.6 \pm 4.8^{*}$ & $55.2 \pm 4.4$ & $38.2 \pm 4.6 *$ & $25.2 \pm 5.8 *$ & $23.0 \pm 6.3 *$ \\
\hline
\end{tabular}

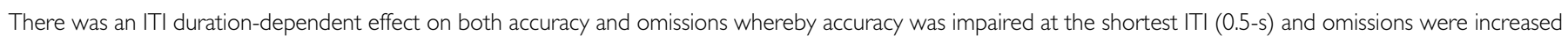
at the shortest ITI compared to the longer ITIs, but Sp-CAMPS did not further affect performance at any ITI.

$* P<0.05$, within-subjects comparison.

Table 4 Effects of Rp-cAMPS on Performance on the Variable-Short Intertrial Interval Version of the 5CSRTT

\begin{tabular}{|c|c|c|c|c|c|c|c|c|}
\hline & \multicolumn{4}{|c|}{ Vehicle } & \multicolumn{4}{|c|}{ Rp-cAMPS (2.1 nmol/0.5 $\mu \mathrm{l}$ per side) } \\
\hline & $0.5-\mathrm{s}$ & I.5-s & 3.0-s & 4.5-s & $0.5-\mathrm{s}$ & I.5-s & 3.0-s & 4.5-s \\
\hline$\%$ Omissions & $60.0 \pm 5.5$ & $43.8 \pm 7.0 *$ & $32.6 \pm 6.4 *$ & $17.9 \pm 4.6^{*}$ & $66.4 \pm 6.1$ & $45.7 \pm 6.3^{*}$ & $33.8 \pm 6.3^{*}$ & $27.4 \pm 6.7 *$ \\
\hline
\end{tabular}

There was an ITI duration-dependent effect on both accuracy and omissions whereby accuracy was impaired at the shortest ITI (0.5-s) and omissions were increased at the shortest ITI compared to the longer ITIs, but Rp-cAMPS did not further affect performance at any ITI.

$* P<0.05$, within-subjects comparison.

As the high dose of Rp-cAMPS increased omissions in addition to decreasing attention under standard testing conditions, we examined the effects of a lower dose $(2.1 \mathrm{nmol} / 0.5 \mu \mathrm{l} / \mathrm{side}$; Table 4$)$ under the challenge conditions. As was the case with rats tested with Sp-cAMPS, there was a main effect of ITI (delay) on accuracy $(\mathrm{F}[3,78]=9.74$, $P<0.01)$ and omissions $(\mathrm{F}[3,78]=69.84, P<0.01)$. Simple main effects tests revealed that accuracy improved as the ITI increased following either vehicle $(\mathrm{F}[3,39]=3.53, P<0.01)$ or Rp-cAMPS $(\mathrm{F}[3,39]=4.78, P<0.01)$ infusions; regardless of treatment, accuracy at the 0.5 -s ITI was lower than at the 3.0- and 4.5-s ITIs ( $P$ values $<0.05$ ). Conversely, simple main effects tests revealed that omissions decreased as the ITI increased following either vehicle $(\mathrm{F}[3,39]=8.98$, $P<0.01)$ or Rp-cAMPS $(\mathrm{F}[3,39]=34.25, P<0.01)$ infusions; regardless of treatment, omissions at the 0.5 -s ITI were greater than at the 1.5-, 3.0-, and 4.5-s ITIs ( $P$ values $<0.05)$. However, there was no main effect of Rp-cAMPS on any performance measure, nor was there a significant interaction between Rp-cAMPS and ITI duration.

To ensure that repeated infusions did not adversely affect 5CSRTT performance, data for the training session on the day preceding the first and last drug infusions were analyzed using paired-samples $t$-tests. Neither accuracy nor omissions were affected by repeated infusions (Table 5).

To examine the possibility that drug diffusion up the guide cannula track contributes to the behavioral effects of the cAMP analogs, infusions were made in the MPFC dorsal to the PrL. Dorsal mPFC infusions of Sp-cAMPS $(2.1 \mathrm{nmol} /$ $0.5 \mu \mathrm{l} / \mathrm{side}, n=5$ ) decreased the latency to respond correctly $(t(4)=2.86, P<0.05$; Table 6$)$, but did not affect any other performance measures. Dorsal mPFC infusions of $\mathrm{Rp}$ cAMPS $(21.0 \mathrm{nmol} / 0.5 \mu \mathrm{l} / \mathrm{side}, n=5)$ increased omissions $(t(4)=3.25, P<0.05$; Table 6$)$, but did not affect any other performance measures. These data establish that the effects of the PKA analogs are more clearly evident when infused into the PrL.
Table 5 Effects of Repeated Drug Infusions on Baseline Performance in the 5CSRTT

\begin{tabular}{lrr}
\hline & First & \multicolumn{1}{c}{ Last } \\
\hline \% Accuracy & $70.5 \pm 1.8$ & $73.7 \pm 1.8$ \\
\% Omissions & $6.4 \pm 0.9$ & $6.8 \pm 1.0$ \\
\hline
\end{tabular}

Baseline performance is defined as the training session on the day prior to drug infusions. Performance did not change from the training session prior to the first drug infusion to the training session prior to the last drug infusion.

\section{PKA and Locomotor Activity}

To address the possibility that nonspecific changes in locomotor activity might contribute to disrupted performance in the 5CSRTT, we assessed the effects of modulating PKA function on behavior in an open field. Intra-PrL infusions of Sp-cAMPS $(2.1 \mathrm{nmol} / 0.5 \mu \mathrm{l} / \mathrm{side}, n=5) \mathrm{did}$ not affect total locomotor activity (Figure $4 \mathrm{a}$, inset). Time-course analysis (Figure $4 \mathrm{a}$, main) revealed that activity decreased during both the habituation $(\mathrm{F}[2$, $16]=100.8, P<0.01)$ and test $(\mathrm{F}[2,16]=43.84, P<0.01)$ elements of the session. Simple main effects tests indicated that both vehicle-treated (habituation, $\mathrm{F}[2,8]=94.46$; test, $\mathrm{F}[2,8]=12.42, \quad P$ values $<0.01)$ and Sp-cAMPStreated (habituation, $\mathrm{F}[2,8]=34.03$; test, $\mathrm{F}[2,8]=41.92$, $P$ values $<0.01)$ rats exhibited a decrease in activity over time. In all cases, rats exhibited more activity in the first 10 -min of a session than in the remainder of the session $(P$ values $<0.01)$.

Intra-PrL infusions of Rp-cAMPS $(21.0 \mathrm{nmol} / 0.5 \mu \mathrm{l} / \mathrm{side}$, $n=5)$ had a session-dependent effect on total locomotor activity $(F[1,8]=6.13, P<0.05$; Figure $4 \mathrm{~b}$, inset). Post hoc analyses indicated that Rp-cAMPS increased locomotor activity compared to that during habituation $(P<0.05)$ and to vehicle infusions $(P<0.01)$. Time-course analysis 
Table 6 Effects of PKA Modulation Within the Dorsal mPFC on Performance in the 5CSRTT

\begin{tabular}{|c|c|c|c|c|c|}
\hline & $\%$ Accuracy & $\%$ Omissions & Premature responses & Magazine entries & Correct latency (s) \\
\hline \multicolumn{6}{|c|}{ Sp-cAMPS } \\
\hline 0 & $68.7 \pm 1.1$ & $10.7 \pm 4.7$ & $19.6 \pm 3.6$ & $124.6 \pm 15.3$ & $0.94 \pm 0.06$ \\
\hline 2.1 & $72.2 \pm 5.4$ & $12.7 \pm 4.3$ & $20.8 \pm 5.2$ & $125.2 \pm 12.3$ & $0.84 \pm 0.09 *$ \\
\hline \multicolumn{6}{|c|}{$R p-c A M P S$} \\
\hline 21 & $71.1 \pm 3.2$ & $18.9 \pm 4.1 *$ & $32.6 \pm 7.8$ & $138.0 \pm 8.4$ & $0.97 \pm 0.11$ \\
\hline
\end{tabular}

Microinfusions were made $1.5 \mathrm{~mm}$ dorsal to the PrL.

*P $<0.05$, within-subjects comparison.
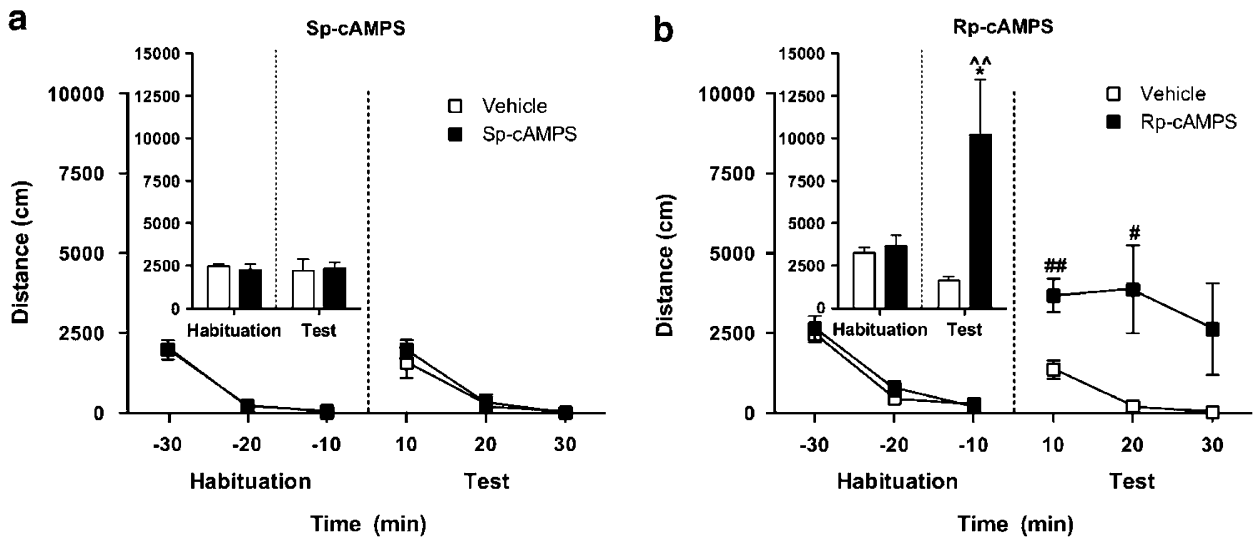

Figure 4 Effects of modulating PKA activity on locomotor activity (mean \pm SEM) in an open field. (a) Sp-cAMPS did not affect total locomotor activity (inset) or the time course of activity (main) during the habituation or test elements of the session. (b) Rp-cAMPS increased total locomotor activity during the test session (inset); effects were particularly evident during the first 20 min (main). $* P<0.0$ I, within-subjects comparison, ${ }^{\wedge} P<<0.0 \mathrm{I}$, between-subjects comparison, Fisher's protected t-tests; ${ }^{\#} P<0.05,{ }^{\# \#} P<0.01$, between-subjects comparison, simple main effects tests.

(Figure $4 \mathrm{~b}$, main) revealed that activity decreased during both the habituation $(\mathrm{F}[2,16]=89.29, P<0.01)$ and test elements of the session $(\mathrm{F}[2,16]=3.61, P<0.05)$. During habituation, activity decreased in both vehicle $(\mathrm{F}[2,8]$ $=53.07, P<0.01)$ and Rp-cAMPS $(\mathrm{F}[2,8]=39.50, P<0.01)$ groups. During the test element of the session, activity decreased in the vehicle $(\mathrm{F}[2,8]=13.48, P<0.01)$, but not in the Rp-cAMPS group. In addition, there was a main effect of drug treatment on activity $(\mathrm{F}[1,16]=6.95$, $P<0.05)$. Simple main effects tests revealed that Rp-cAMPS increased activity relative to vehicle at both the $10-\min (\mathrm{F}[1$, $8]=3.93, P<0.01)$ and $20-\min (\mathrm{F}[1,8]=2.66, P<0.05)$ time points.

\section{PKA and Brain Stimulation Reward}

Microinfusions of a D1 receptor antagonist into the PFC can affect motivation as assessed in the ICSS test (Duvauchelle et al, 1998). As such, we used the ICSS test to address the possibility that nonspecific changes in motivation to respond for rewarding stimuli (ie, the sugar pellets) might contribute to altered performance in the 5CSRTT. Intra-PrL microinfusions of Sp-cAMPS $(n=8)$ did not affect reward thresholds (Figure 5a). However, Sp-cAMPS decreased maximal rates of responding for brain stimulation reward $(t[7]=3.32, P<0.01$; Figure $5 b)$, an effect typically seen with treatments that reduce the capacity to respond rather than the rewarding impact of the stimulation (Miliaressis et al, 1982; Carlezon and Chartoff, 2007). In contrast, intraPrL infusions of Rp-cAMPS $(n=8)$ did not affect reward thresholds (Figure 5c) or maximum rates of responding (Figure 5d).

\section{CREB and Performance in the 5CSRTT}

We used viral-mediated gene transfer of wild-type CREB to elevate CREB function (a downstream consequence of SpcAMPS; Self et al, 1998) or mCREB to disrupt CREB function (a downstream consequence of Rp-cAMPS; Self et al, 1998) to examine how alterations in the activity of this transcription factor in the PrL affects attention (Figure 6; Table 7). There was a significant interaction between viral vector treatment and session on accuracy $(\mathrm{F}[2,57]=4.50$, $P<0.05$; Figure 6a). Post hoc analyses indicated that expression of mCREB (which disrupts CREB function; Carlezon et al, 1998; $n=10)$ impaired accuracy $(P<0.01)$, whereas elevated expression of CREB $(n=9)$ or $\beta$-galactosidase $(n=9)$ had no effect. Likewise, there was a significant interaction between viral vector treatment and session on omissions $(\mathrm{F}[2,57]=3.59, P<0.05$; Figure $6 \mathrm{~b})$. Post hoc analyses indicated that expression of mCREB increased omissions $(P<0.01)$, whereas elevated expression 
a

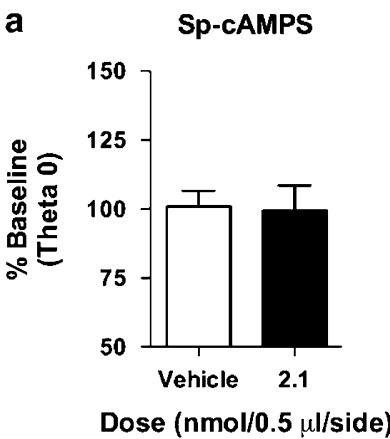

b

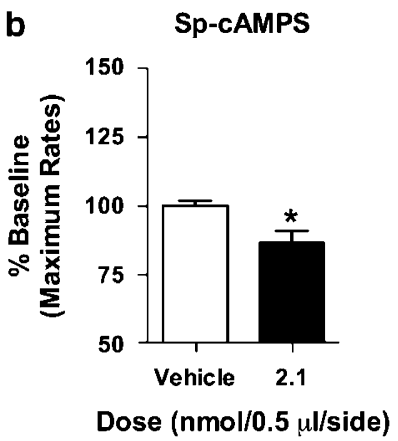

C

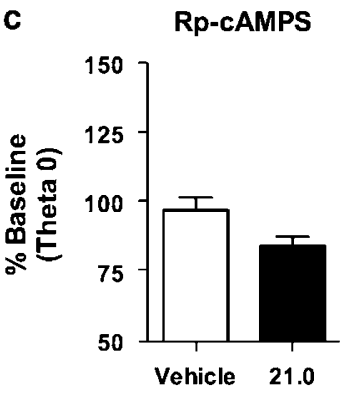

Dose (nmol/0.5 $\mu \mathrm{l} / \mathrm{side})$

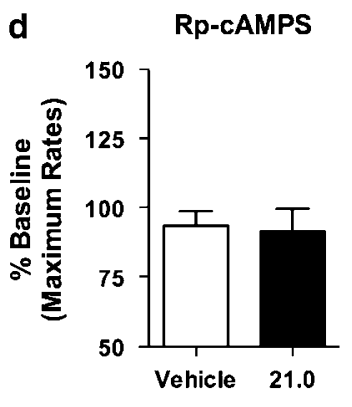

Dose (nmol/ $0.5 \mu \mathrm{l} / \mathrm{side})$

Figure 5 Effects of modulating PKA activity on ICSS. (a) Sp-CAMPS did not affect reward thresholds (mean \pm SEM), but (b) reduced maximum rates of responding. (c) Rp-cAMPS did not affect reward thresholds or (d) maximum rates of responding. $* P<0.05$ compared to vehicle, Student's $t$-test.
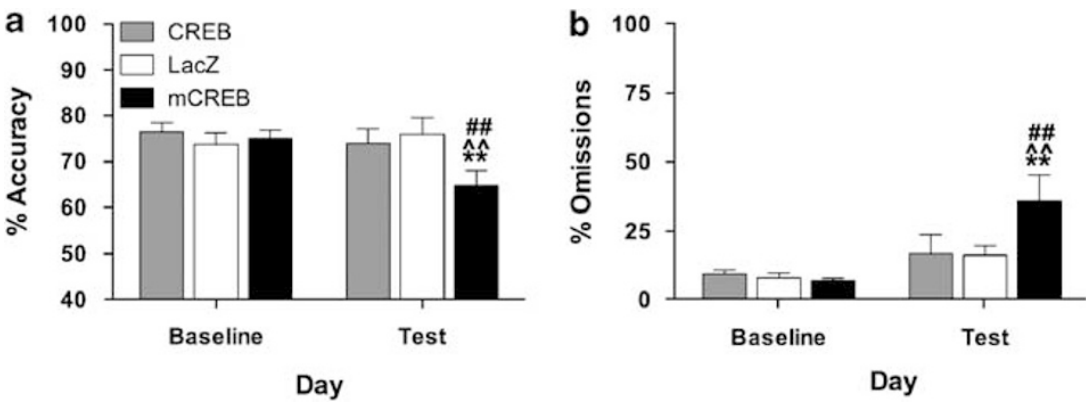

Figure 6 Effects of modulating CREB function on 5CSRTT performance. Expression of mCREB impaired accuracy (mean \pm SEM) (a) and increased omissions (b). ${ }^{*} * P<0.0$ I, within-subjects comparison to baseline; ${ }^{\wedge} \wedge P<0.0$ l, between-subjects comparison to LacZ; ${ }^{\# \#} P<0.01$, between-subjects comparison with CREB, Fisher's protected t-tests.

Table 7 Effects of Intra-PrL Modulation of CREB Function on 5CSRTT Performance

\begin{tabular}{lccc}
\hline & CREB & LacZ & mCREB \\
\hline $\begin{array}{l}\text { Premature responses } \\
\text { Baseline }\end{array}$ & $15.1 \pm 3.5$ & $18.9 \pm 3.3$ & $23.9 \pm 3.9$ \\
$\quad$ Test & $11.8 \pm 1.5$ & $10.0 \pm 2.5$ & $15.0 \pm 4.2$ \\
& & & \\
Magazine entries & & & \\
$\quad$ Baseline & $217.8 \pm 33.8$ & $205.7 \pm 19.8$ & $227.7 \pm 21.7$ \\
$\quad$ Test & $217.3 \pm 35.4$ & $180.9 \pm 17.8$ & $207.7 \pm 54.0$ \\
& & & \\
Correct response latency & & & \\
$\quad$ Baseline & $0.82 \pm 0.03$ & $0.76 \pm 0.04$ & $0.83 \pm 0.05$ \\
$\quad$ Test & $0.98 \pm 0.08 *$ & $0.90 \pm 0.07^{\dagger}$ & $1.07 \pm 0.10^{* * *}$ \\
\hline
\end{tabular}

Baseline values consisted of the average performance on the 3 sessions prior to surgery.

${ }^{*} P<0.05,{ }^{*} * *<0.01,{ }^{\dagger} P<0.1$, within-subjects comparison.

of CREB or $\beta$-galactosidase had no effect. There was a main effect of viral vector treatment on correct response latency $(\mathrm{F}[2,57]=26.85, P<0.01$; Table 7$)$. Simple main effects tests showed the correct response latency was increased following vector infusions of CREB $(\mathrm{F}[1,8]=7.29, P<0.05)$ and $\operatorname{mCREB}(\mathrm{F}[1,9]=16.32, P<0.01)$, with a trend toward an increase in the $\operatorname{LacZ}$ group $(\mathrm{F}[1,8]=3.42, P=0.10)$, likely reflecting nonspecific effects of the relatively short period of recovery following surgery that is necessary when using HSV vectors (Carlezon et al, 2000). None of the other performance measures were affected by the viral vector treatments (Table 7).

To examine if manipulating CREB function within the PrL affects accuracy in a baseline-dependent fashion, we used a median-split to divide the groups of rats treated with the CREB, LacZ, and MCREB vectors into 'good' and 'poor' performance groups based on baseline accuracy: in this dataset, rats performing at $\geqslant 75 \%$ accuracy were defined as 'good' performers whereas those performing at $<75 \%$ accuracy were defined as 'poor' performers $(n=3-7)$. Manipulations of CREB function did not affect accuracy or omissions in a baseline-dependent fashion (data not shown).

\section{CREB and Locomotor Activity}

To determine the extent to which manipulations of CREB function within the PrL mimicked manipulations of PKA function, we also examined the effects of the CREB $(n=6)$, mCREB $(n=5)$, or LacZ $(n=5)$ vectors on locomotor activity (Figure 7). There was a significant effect of session (baseline $v s$ test) on total locomotor activity ( $\mathrm{F}[1$, $13]=26.26, P<0.01$; Figure 7 , inset). Simple main effects test revealed that activity was higher during the baseline session than during the test session in all treatment groups $(\mathrm{CREB}, \mathrm{F}[1,5]=8.24 ; \mathrm{LacZ}, \mathrm{F}[1,4]=8.82 ; \mathrm{mCREB}, \mathrm{F}[1$, $4]=12.67, P$ values $<0.01$ ). Time-course analysis (Figure 7 , 


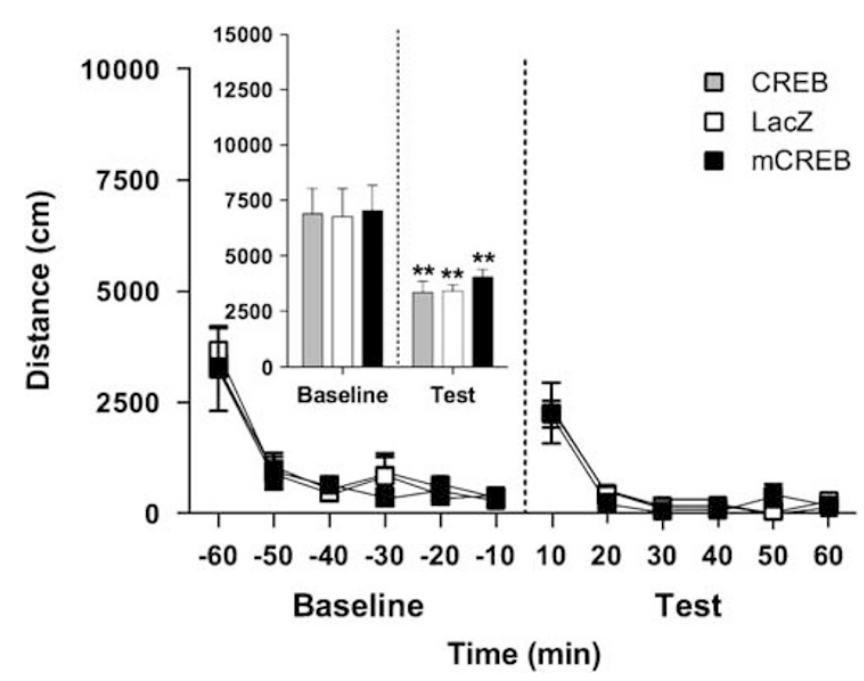

Figure 7 Effects of modulating CREB function on locomotor activity (mean \pm SEM). Manipulations of CREB function did not differentially affect total activity levels, although activity was lower in all groups during the test session. $* * P<0.01$, within-subjects comparisons, simple main effects tests.

main) revealed a main effect of time in both the baseline $(\mathrm{F}[5,65]=46.88, \quad P<0.01)$ and test sessions $(\mathrm{F}[5$, $65]=52.88, P<0.01)$. Simple main effects tests revealed that activity decreased progressively within the baseline (CREB, F[5, 25] $=22.96$; LacZ, F $[5,20]=20.32$; mCREB F $[5$, $20]=9.16, P$ values $<0.01)$ and test sessions $(\mathrm{CREB}, \mathrm{F}[5$, $25]=27.53$; LacZ, $\mathrm{F}[5,20]=41.14$; mCREB, $\mathrm{F}[5,20]=8.69$, $P$ values $<0.01)$. In all cases, activity was highest in the first 10-min relative to the remainder of the session $(P$ values $<0.01)$. However, there were no systematic differences among the groups at any time point.

\section{DISCUSSION}

Altered PKA function within the mPFC affected attention in rats, as measured in the 5CSRTT. A comparison of two microinfusion sites within the MPFC localized the strongest effects to the PrL. Our data are consistent with previous evidence that lesions of the mPFC that involve the PrL produce similar attention deficits in the 5CSRTT (Chudasama et al, 2003; Passetti et al, 2002). Stimulation of PKA (by Sp-cAMPS) had negligible effects on accuracy - an index of whether the rats respond correctly during trials in which they make a response- under standard (training) conditions, whereas PKA inhibition (by Rp-cAMPS) disrupted accuracy. However, both activation and inhibition of PKA in the PrL caused similar $(\sim 300 \%)$ increases in omission errors, reflecting the number of trials in which the rats failed to respond. Omission errors increased without corresponding decreases in the number of premature responses or magazine entries, and without increases in the correct response latency. It is therefore unlikely that omission errors increased because of a general disruption in the ability to sequence behaviors necessary to perform the 5CSRTT. The increase in omission errors after both analogs suggests that we tested behaviorally active concentrations of each. Despite similar effects on some measures of performance, additional tests distinguished these treatments.
Open-field tests revealed that PKA stimulation in the PrL did not affect locomotor activity, whereas PKA inhibition caused sustained hyperactivity. ICSS tests revealed that neither PKA stimulation nor inhibition in the PrL affected thresholds to respond for rewarding brain stimulation, indicating lack of effects on motivation. However, PKA stimulation significantly reduced maximal rates of ICSS (a motorically demanding task in which rats typically make $>60$ responses $/ \mathrm{min}$ ), indicating a diminished capacity to respond at high rates (Carlezon and Chartoff, 2007). These additional studies rule out the possibility that nonspecific effects shared by Sp-cAMPS and Rp-cAMPS explain the increased omission errors. When data from all of these studies are considered together, they suggest that PKA inhibition within the mPFC causes disruptions in accurate performance that are accompanied by hyperactivity, whereas stimulation of PKA in this area does not affect accuracy but disrupts the capacity to respond in tasks requiring complex motor output.

\section{CREB-Mediated Effects}

Disruption of CREB function had effects on attention that were similar to those of PKA inhibition. PKA activation has immediate effects that include phosphorylation of ion channels, receptor proteins, and transcription factors including CREB (Greengard et al, 1999). Phosphorylation of AMPA or NMDA receptor subunits promotes membrane insertion and neuronal activity (Carvalho et al, 2000; Song and Huganir, 2002; Dudman et al, 2003). Phosphorylation of NMDA receptor subunits also affects their calcium permeability (Skeberdis et al, 2006). Presumably, RpcAMPS-mediated decreases in PKA function has opposite effects, acutely attenuating surface expression of excitatory receptors, thereby reducing the effects of D1 receptor stimulation on neuronal activity (Dong and White, 2003). In contrast, CREB-mediated gene transcription peaks 20$30 \mathrm{~min}$ following increased PKA activity (Mayr and Montminy, 2001), indicating that our behavioral tests involving the cAMPS analogs likely occurred during CREB-regulated gene transcription but before translation. Nonetheless, the functional effects of acute increases in PKA activity and sustained increases in CREB function are similar: both increase neuronal excitability (TranthamDavidson et al, 2004, 2008; Dong et al, 2006; Lopez de Armentia et al, 2007). Expression of mCREB reduces neuronal excitability (Dong et al, 2006), suggesting that this effect in the PrL is associated with disrupted attention. The effects of altering CREB function appear to be mediated, at least in part, via effects on gene transcription (including voltage-gated sodium- and potassium-channel subunits; McClung and Nestler, 2003). Although the consequences of decreased PKA activation and reduced CREB function on attention likely require different time courses and might involve separate mechanisms, the present findings raise the possibility that both impair attention via common effects on neuronal activity. The disparate effects of reduced PKA and CREB function on behavior in an open field might indicate that inattention and hyperactivity depend on different PKA-regulated targets. Regardless, the present work identifies a common 
behavioral effect of acute reduction of PKA activity and sustained reduction of CREB function within the MPFC.

\section{The 5CSRTT}

It is important to emphasize that the standard (consistent ITI) testing parameters used here are sensitive to both decreases and increases in performance (Paine et al, 2007). For example, the NMDA receptor antagonist MK-801 and the kappa-opioid receptor agonist U69593 each degrade performance in the 5CSRTT, although neither produced the same patterns as seen with the cAMP analogs. MK-801 decreases accuracy and increases omissions (similar to RpcAMPS), but it also increases premature responding. In contrast, U69 593 increases omissions (similar to both SpcAMPS and Rp-cAMPS); however, it likely does so by decreasing the rewarding impact of the food (sugar pellets) that motivates performance in this task, because the drug also decreases the rewarding impact of lateral hypothalamic brain stimulation (Todtenkopf et al, 2004). Importantly, the doses of U69 593 that cause omission errors in the 5CSRTT are four-fold higher than those required to elevate ICSS thresholds, suggesting that our studies have sufficient sensitivity to detect motivational deficits caused by the cAMP analogs. Although Sp-cAMPS reduced maximal rates of ICSS, this occurred independently of changes in ICSS thresholds, suggesting nonspecific decreases in the capacity to respond rather than decreases in motivation (Carlezon et al, 2007). Thus unlike the case with U69593, the effects of Sp-cAMPS and Rp-cAMPS on performance in the 5CSRTT do not appear to reflect general alterations in motivation. We have also found that methylphenidate (a stimulant treatment for attention deficit-hyperactivity disorder (ADHD)) can improve accuracy and that desipramine (a norepinerphine reuptake inhibitor similar to atomoxetine, a nonstimulant treatment for ADHD) can reduce premature responding, a behavior often considered to reflect impulsivity (Paine et al, 2007).

In addition to accuracy, omission errors, and premature responding, we also analyzed latency to make a correct response (thought to reflect the ability to initiate a motor response) and food-magazine entries (thought to reflect perseverative responding). Neither cAMP analog affected these measures, suggesting that the cAMP analogs did not affect the sequencing of behaviors necessary to perform the 5CSRTT. However, all treatments in the viral vector studies tended to elevate latencies to make a correct response. The effect was mild and likely reflects a nonspecific effect of recovery from the surgical procedures rather than a common effect of the gene products encoded by the vectors. Use of HSV vectors, which cause rapid but transient alterations in transgene expression (Carlezon et al, 2000), make it necessary to test within the time frame we used here.

We conducted post hoc analyses in which we examined the effects of the cAMP analogs on accuracy after using median splits to classify the rats as 'good' or 'poor' performers. PKA inhibition selectively impaired accuracy in 'good' performers whereas the reductions in accuracy produced by mCREB were not baseline-dependent, perhaps owing to the sustained nature of this manipulation. We also assessed PKA effects on accuracy by challenging rats with a more demanding regimen involving short and unpredictable ITIs. We used a sub-threshold dose of Rp-cAMPS to determine if increasing the difficulty of the task would increase susceptibility to PKA disruption. Under these conditions we found significant time (ITI)-dependent decrements in performance, but no additional effects of Rp-cAMPS (or Sp-cAMPS), suggesting that a threshold degree of PKA inhibition must be surpassed to reduce accuracy.

\section{Attention and Working Memory}

Our findings with Rp-cAMPS are consistent with previous reports that D1 receptor antagonists decrease accuracy in 'good' performers (Granon et al, 2000). However, our findings with Sp-cAMPS are not consistent with the reports that D1 receptor agonists improve attention in 'poor' performers and under demanding test conditions (Granon et al, 2000, Chudasama and Robbins, 2004). Moreover, unlike the current findings, these manipulations of D1 receptor activity did not affect the number of omission errors (Granon et al, 2000, Chudasama and Robbins, 2004), suggesting that other D1-associated signaling pathways (eg, inositol triphosphate $\left(\mathrm{IP}_{3}\right)$; Undie and Friedman, 1990) might also influence performance. Surprisingly, the effects of modulating PKA activity on attention appear opposite to those on working memory. We found that PKA inhibition impaired attention, whereas previous reports indicate that it can improve working memory (Arnsten et al, 2005; Ramos et al, 2003). Furthermore, we found that PKA activation had negligible effects on attention, whereas these other reports indicate that it impaired working memory. In the 5CSRTT, the time from stimulus onset to a response tends to be short $(<1 s)$ and may not require working memory. Indeed, PKA activation impairs working memory after longer delays (>20 s; Taylor et al, 1999). Similarly, whereas the duration of the cue presentation in the 5CSRTT is short (0.5-1.0 s), the duration cue of exposure in maze-based working memory tasks tends to be longer $(\sim 5 \mathrm{~s})$. Attention might be impaired following PKA activation in tasks employing a greater working memory load, and working memory might be impaired by PKA inhibition in tasks where the stimulus is shorter.

\section{Modeling Human Attention Disorders}

ADHD is characterized by inattention, hyperactivity, and impulsivity (American Psychiatric Association, 2000). We report that PKA inhibition within the $\mathrm{MPFC}$ of rats produces two hallmark signs of ADHD in humans: reduced accuracy in attention tasks and elevated activity levels. Amphetamine-like stimulants would be expected to offset reduced activity of PKA and downstream targets (eg, CREB) by increasing D1 receptor stimulation (Turgeon et al, 1997; Greengard et al, 1999; Carlezon et al, 2005). Activation of PKA might also be accomplished via other mechanisms (eg, stimulation of other $\mathrm{G}_{\mathrm{s}}$-coupled receptors, inhibition of cyclic nucleotide phosphodiesterases (PDEs)). However, PKA inhibition did not increase impulsivity (premature responses) in the 5CSRTT. If anything, stimulation of PKA within the $\mathrm{MPFC}$ increased premature responding, although this trend did not reach statistical significance. These 
findings raise the possibility that ADHD involves PKA dysregulation within the $\mathrm{MPFC}$, and that the constellation of clinical symptoms reflects abnormal fluctuations in kinase activity. Future work might help to determine if inhibition of PKA within the mPFC could be utilized to model ADHD; a particularly important next step is to explore whether treatments that improve attention in people diagnosed with this condition (eg, methylphenidate, amphetamine, atomoxetine) can reverse Rp-cAMPS-induced inattention and hyperactivity. Improved animal models will facilitate the development of treatments for psychiatric disorders that more selectively target pathophysiology.

\section{ACKNOWLEDGEMENTS}

This study was funded by a NARSAD Young Investigator Award (to TAP) and a grant from the National Institute of Mental Health (MH063266, to WAC).

\section{DISCLOSURE}

Dr Carlezon has a US patent and several US patent applications for novel treatments for depressive disorders. $\mathrm{He}$ has received compensation from Huya Bioscience, Infinity Pharmaceuticals, Myneurolab.com, and Psychogenics. Dr Paine and Dr Neve have nothing to disclose.

\section{REFERENCES}

American Psychiatric Association (2000). Diagnostic and Statistical Manual-Text Revision. American Psychiatric Association: Washington, DC.

Arnsten AFT, Ramos BP, Birnbaum SG, Taylor JR (2005). Protein kinase $\mathrm{A}$ as a therapeutic target for memory disorders: rationale and challenges. Trends Mol Med 11: 121-128.

Aujla H, Beninger RJ (2001). Hippocampal-prefrontocortical circuits: PKA inhibition in the prefrontal cortex impairs delayed nonmatching in the radial maze in rats. Behav Neurosci 115: 1204-1211.

Birrell JM, Brown VJ (2000). Medial frontal cortex mediates perceptual attentional set shifting in the rat. J Neurosci 20: 4320-4324.

Carlezon Jr WA, Boundy VA, Haile CN, Lane SB, Kalb RG, Neve RL et al (1997). Sensitization to morphine induced by viralmediated gene transfer. Science 277: 812-814.

Carlezon Jr WA, Chartoff EH (2007). Intracranial self-stimulation (ICSS) in rodents to study the neurobiology of motivation. Nat Protoc 2: 2987-2995.

Carlezon Jr WA, Duman RS, Nestler EJ (2005). The many faces of CREB. Trends Neurosci 28: 436-445.

Carlezon Jr WA, Nestler EJ, Neve RL (2000). Herpes simplex virusmediated gene transfer as a tool for neuropsychiatric disease. Crit Rev Neurobiol 14: 47-67.

Carlezon Jr WA, Thome J, Olson VG, Lane-Ladd SB, Brodkin ES, Hiroi $N$ et al (1998). Regulation of cocaine reward by CREB. Science 282: 2272-2275.

Carvalho AL, Duarte CB, Carvalho AP (2000). Regulation of AMPA receptors by phosphorylation. Neurochem Res 25: 1245-1255.

Chudasama Y, Passetti F, Rhodes SE, Lopian D, Desai A, Robbins TW (2003). Dissociable aspects of performance on the 5-choice serial reaction time task following lesions of the dorsal anterior cingulate, infralimbic and orbitofrontal cortex in the rat: differential effects on selectivity, impulsivity and compulsivity. Behav Brain Res 146: 105-119.
Chudasama Y, Robbins TW (2004). Dopaminergic modulation of visual attention and working memory in the rodent prefrontal cortex. Neuropsychopharmacology 29: 1628-1636.

Dong Y, Green T, Saal D, Marie H, Neve R, Nestler EJ et al (2006). CREB modulates excitability of nucleus accumbens neurons. Nat Neurosci 9: 475-477.

Dong Y, White FJ (2003). Dopamine D1-class receptors selectively modulate a slowly inactivating potassium current in rat medial prefrontal cortex pyramidal neurons. J Neurosci 23: 2686-2695.

Dudman JT, Eaton ME, Rajadhyaksha A, Macías W, Taher M, Barczak A et al (2003). Dopamine D1 receptors mediate CREB phosphorylation via phosphorylation of the NMDA receptor at Ser897-NR1. J Neurochem 87: 922-934.

Duvauchelle CL, Fleming SM, Kornetsky C (1998). Prefrontal cortex infusions of SCH 23390 cause immediate and delayed effects on ventral tegmental area stimulation reward. Brain Res 811: 57-62.

Floresco SB, Phillips AG (2001). Delay-dependent modulation of memory retrieval by infusion of a dopamine $D_{1}$ agonist into the rat medial prefrontal cortex. Behav Neurosci 115: 934-939.

Goldman-Rakic PS, Muly III EC, Williams GV (2000). D 1 receptors in prefrontal cells and circuits. Brain Res Brain Res Rev 31: 295-301.

Granon S, Passetti F, Thomas KL, Dalley JW, Everitt BJ, Robbins TW (2000). Enhanced and impaired attentional performance after infusion of D1 dopaminergic receptor agents into rat prefrontal cortex. J Neurosci 20: 1208-1215.

Greengard P, Allen PB, Nairn AC (1999). Beyond the dopamine receptor: the DARPP-32/protein phosphatase-1 cascade. Neuron 23: 435-447.

Lidlow MS, Koh P-O, Arnsten AFT (2003). D1 dopamine receptors in the mouse prefrontal cotex: immunocytochemical and cognitive neuropharmacological analyses. Synapse 47: 101-108.

Lopez de Armentia M, Jancic D, Olivares R, Alarcon JM, Kandel ER, Barco A (2007). cAMP response element-binding proteinmediated gene expression increases the intrinsic excitability of CA1 pyramidal neurons. J Neurosci 27: 13909-13918.

Mayr B, Montminy M (2001). Transcriptional regulation by the phosphorylation-dependent factor CREB. Nat Rev Mol Cell Biol 2: 599-609.

McClung CA, Nestler EJ (2003). Regulation of gene expression and cocaine reward by CREB and DeltaFosB. Nat Neurosci 6: 1208-1215.

Miliaressis E, Rompré PP, Durivage A (1982). Psychophysical method for mapping behavioral substrates using a moveable electrode. Brain Res Bull 8: 693-701.

Muir JL, Everitt BJ, Robbins TW (1996). The cerebral cortex of the rat and visual attentional function: dissociable effects of mediofrontal, cingulate, anterior dorsolateral, and parietal cortex lesions on a five-choice serial reaction time task. Cereb Cortex 6: 470-481.

National Academy Press (1996). Guide for the Care and Use of Laboratory Animals. National Academy Press: Washington, DC.

Neumaier JF, Vincow ES, Arvanitogiannis A, Wise RA, Carlezon Jr WA (2002). Elevated expression of 5-HT1B receptors in nucleus accumbens efferents sensitizes animals to cocaine. J Neurosci 22 10856-19863.

Neve RL, Howe JR, Hong S, Kalb RG (1997). Introduction of the glutamate receptor subunit 1 into motor neurons in vitro and in vivo using recombinant herpes simplex virus. Neuroscience 79: 435-447.

Paine TA, Tomasiewicz HC, Zhang K, Carlezon Jr WA (2007). Sensitivity of the five-choice serial reaction time task to the effects of various psychotropic drugs in Sprague-Dawley rats. Biol Psychiatry 62: 687-693.

Passetti F, Chudasama Y, Robbins TW (2002). The frontal cortex of the rat and visual attentional performance: dissociable functions of distinct medial prefrontal subregions. Cereb Cortex 12: $1254-1268$. 
Paxinos G, Watson C (1997). The Rat Brain in Stereotaxic Coordinates, 3rd edn. Academic Press: Orlando, FL.

Pliakas AM, Carlson RR, Neve RL, Konradi C, Nestler EJ, Carlezon Jr WA (2001). Altered responsiveness to cocaine and increased immobility in the forced swim test associated with elevated cAMP response element-binding protein expression in nucleus accumbens. J Neurosci 21: 7397-7403.

Ramos BP, Birnbaum SG, Lindenmayer I, Newton SS, Duman RS, Arnsten AF (2003). Dysregulation of protein kinase a signaling in the aged prefrontal cortex: new strategy for treating agerelated cognitive decline. Neuron 40: 835-845.

Robbins TW (2002). The 5-choice serial reaction time task: behavioural pharmacology and functional neurochemistry. Psychopharmacology (Berl) 163: 362-380.

Rosvold HE, Mirsky AF, Saranson I, Bransome EB, Beck LH (1956). A continuous performance test of brain damage. J Consult Psychol 20: 343-350.

Runyan JD, Dash PK (2005). Distinct prefrontal molecular mechanisms for information storage lasting seconds $v s$ minutes. Learn Mem 12: 232-238.

Self DW, Genova LM, Hope BT, Barnhart WJ, Spencer JJ, Nester EJ (1998). Involvement of cAMP-dependent protein kinase in the nucleus accumbens in cocaine self-administration and relapse of cocaine-seeking behavior. J Neurosci 18: 1848-1859.

Skeberdis VA, Chevaleyre V, Lau CG, Goldberg JH, Pettit DL, Suadicani SO et al (2006). Protein kinase A regulates calcium permeability of NMDA receptors. Nat Neurosci 9: 501-510.

Song I, Huganir RL (2002). Regulation of AMPA receptors during synaptic plasticity. Trends Neurosci 25: 578-588.
Taylor JR, Birnbaum S, Ubriani R, Arnsten AFT (1999). Activation of cAMP-dependent protein kinase $\mathrm{A}$ in prefrontal cortex impairs working memory performance. J Neurosci 19: RC23 (1-5).

Todtenkopf MS, Marcus JF, Portoghese PS, Carlezon Jr WA (2004). Effects of kappa-opioid receptor ligands on intracranial self-stimulation in rats. Psychopharmacology (Berl) 172: 463-470.

Todtenkopf MS, Parsegian A, Naydenov A, Neve RL, Konradi C, Carlezon Jr WA (2006). Brain reward regulated by AMPA receptor subunits in nucleus accumbens shell. J Neurosci 26: 11665-11669.

Trantham-Davidson H, Kröner S, Seamans JK (2008). Dopamine modulation of prefrontal cortex interneurons occurs independently of DARPP-32. Cereb Cortex 18: 951-958.

Trantham-Davidson H, Neely LC, Lavin A, Seamans JK (2004). Mechanisms underlying differential D1 vs D2 dopamine receptor regulation of inhibition in prefrontal cortex. J Neurosci 24: 10652-10659.

Turgeon SM, Pollack AE, Fink JS (1997). Enhanced CREB phosphorylation and changes in c-Fos and FRA expression in striatum accompany amphetamine sensitization. Brain Res 749: $120-126$.

Undie AS, Friedman E (1990). Stimulation of a dopamine D1 receptor enhances inositol phosphates formation in rat brain. J Pharmacol Exp Ther 253: 987-992.

Zahrt J, Taylor JR, Mathew RG, Arnsten AFT (1997). Supranormal stimulation of $D_{1}$ dopamine receptors in the rodent prefrontal cortex impairs spatial working memory performance. J Neurosci 17: $8528-8535$. 